\title{
Dynamical observation of bamboo-like carbon nanotube growth
}

Ming Lin, ${ }^{\dagger}$ Joyce Pei Ying Tan, ${ }^{\dagger}$ Chris Boothroyd, ${ }^{\dagger}$ Kian Ping Loh, ${ }^{\dagger \dagger}$ Eng Soon Tok, ${ }^{\dagger}$ and Yong$\operatorname{Lim}_{\text {Foo }}^{\dagger, *}$

${ }^{\dagger}$ Institute of Materials Research and Engineering, 3 Research Link, S1 1760, Singapore

${ }^{\dagger}$ Department of Chemistry, National University of Singapore, 3 Science Drive 3, S117543, Singapore

${ }^{*}$ Department of Physics, National University of Singapore, 2 Science Drive 3, S117542, Singapore

\section{Supporting information}

\# See also supporting movie 1 (complete BCNT knot) and movie 2 (incomplete BCNT knot) formation.

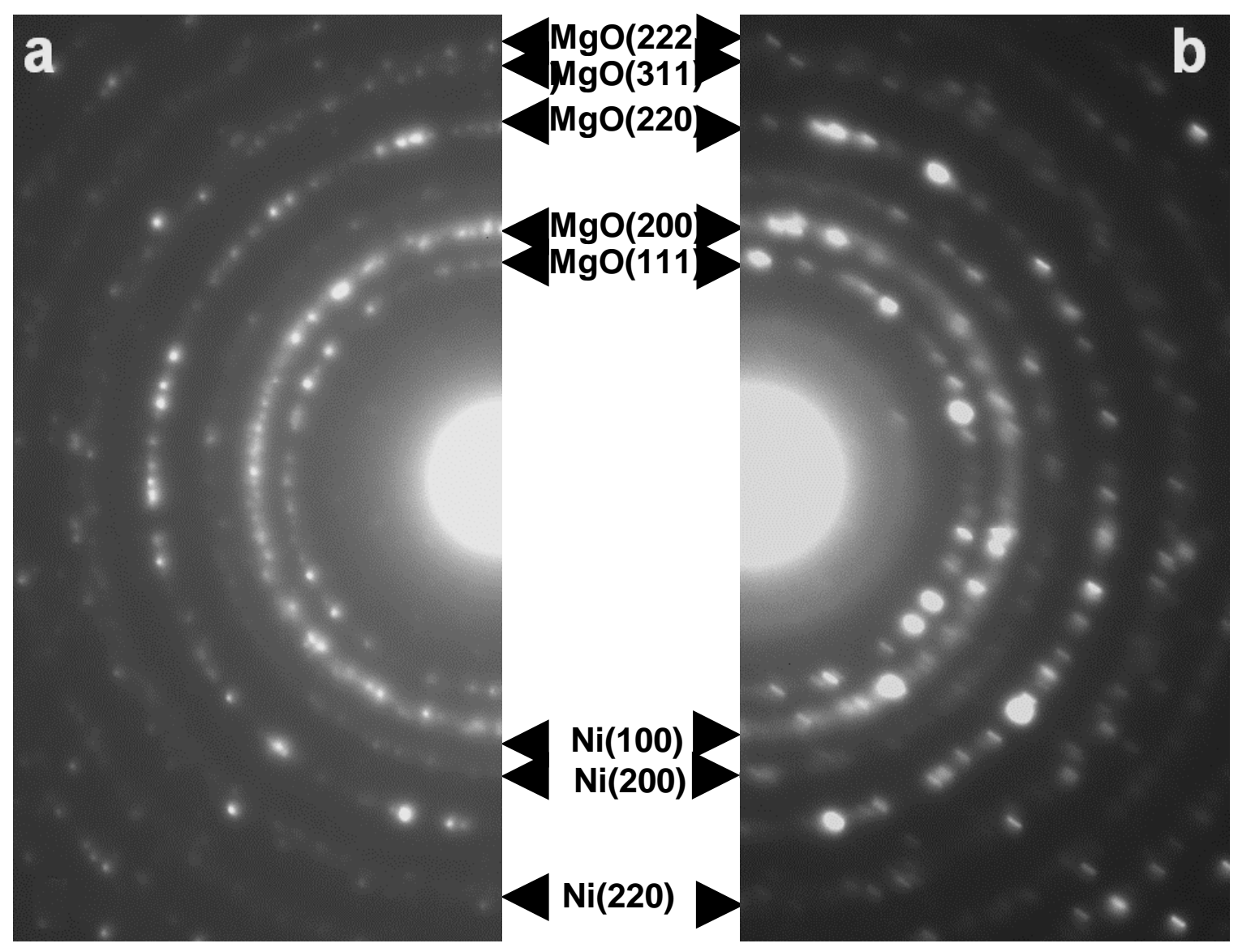

Fig S1 Selected area diffraction pattern of Ni-MgO catalyst (a) during (b) after CNT growth. It is shown that no $\mathrm{Ni}_{3} \mathrm{C}$ phase was observed in the spectrum.

\footnotetext{
* Corresponding email: yl-foo@imre.a-star.edu.sg
} 

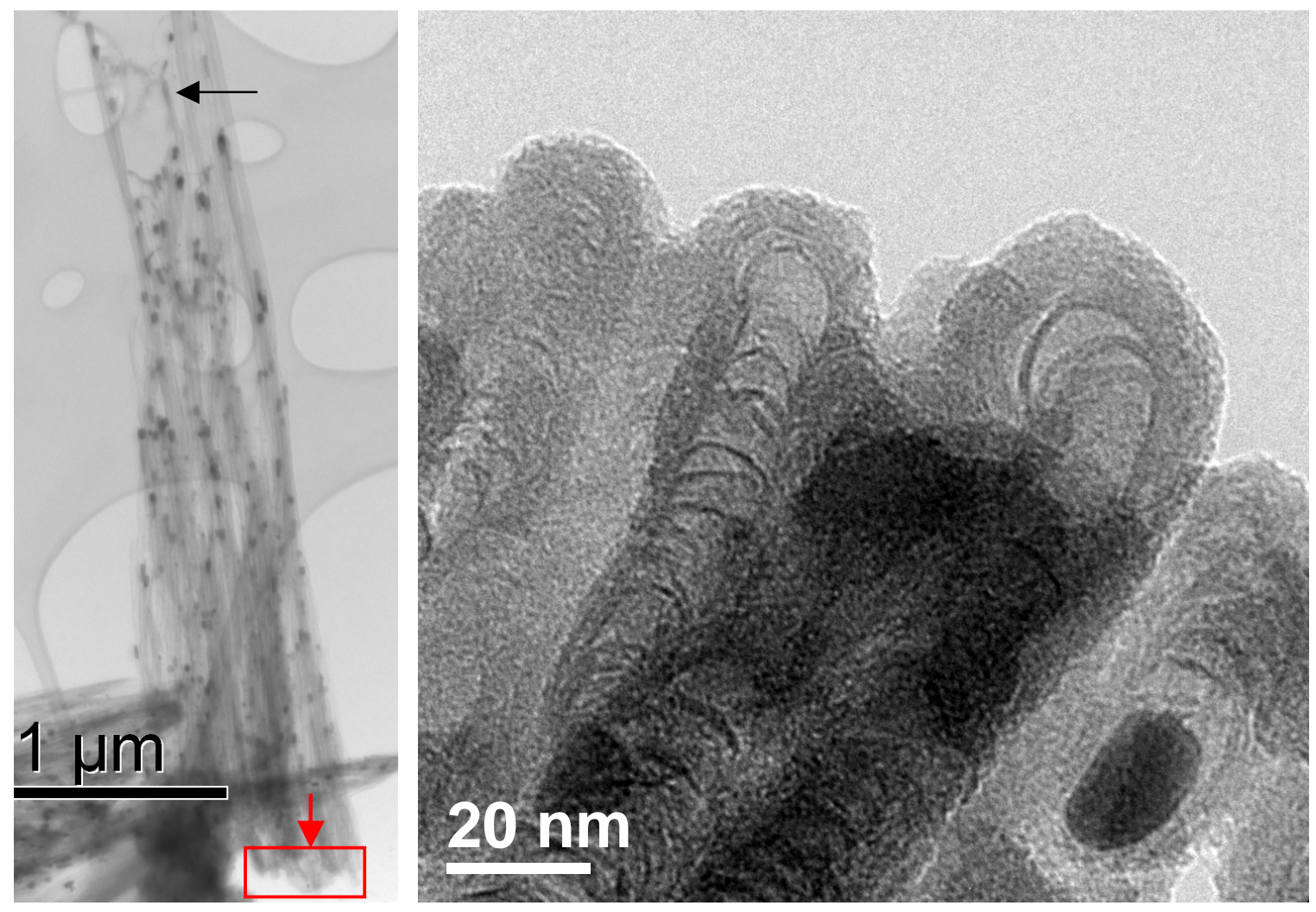

Fig S2. Bright field TEM images of (a) an overview of a bundle of bamboo-like carbon nanotubes, which is acquired in an ex-situ DC plasma furnace; (b) magnified root of the tubes. The bundle of nanotubes resembles like a cone, where sharp end is the tip, while flat support is the root. Detailed information can be found in the Diamond and Related. Materials (Tan, C. K.; Loh, K. P.; Thong, J. T. L.; Soh, C. H.; Zhang, H. 2005, 14, 902). It is shown that closed caps are commonly existed at the root of carbon nanotubes, which is assisted by tip-growth mode. In such cases, the dangling bond of graphite can be minimized by the formation of the caps. The formation of energy of a completed hemispherical cap is estimated at $2.91 \mathrm{eV}$ in the in-situ TEM experiment. 